\title{
Selection for phenotypic plasticity in Rana sylvatica tadpoles
}

\author{
JOSH VAN BUSKIRK ${ }^{1}$ AND RICK A. RELYEA \\ Department of Biology, University of Michigan, Ann Arbor, MI 48109, U.S.A.
}

Received 12 February 1998; accepted for publication 20 June 1998

\begin{abstract}
The hypothesis that phenotypic plasticity is an adaptation to environmental variation rests on the two assumptions that plasticity improves the performance of individuals that possess it, and that it evolved in response to selection imposed in heterogeneous environments. The first assumption has been upheld by studies showing the beneficial nature of plasticity. The second assumption is difficult to test since it requires knowing about selection acting in the past. However, it can be tested in its general form by asking whether natural selection currently acts to maintain phenotypic plasticity. We adopted this approach in a study of plastic morphological traits in larvae of the wood frog, Rana sylvatica. First we reared tadpoles in artificial ponds for 18 days, in either the presence or absence of Anax dragonfly larvae (confined within cages to prevent them from killing the tadpoles). These conditioning treatments produced dramatic differences in size and shape: tadpoles from ponds with predators were smaller and had relatively short bodies and deep tail fins. We estimated selection by Anax on the two kinds of tadpoles by testing for non-random mortality in overnight predation trials. Dragonflies imposed strong selection by preferentially killing individuals with relatively shallow and short tail fins, and narrow tail muscles. The same traits that exhibited the strongest plasticity were under the strongest selection, except that tail muscle width exhibited no plasticity but experienced strong increasing selection. A laboratory competition experiment, testing for selection in the absence of predators, showed that tadpoles with deep tail fins grew relatively slowly. In the cattle tanks, where there were also no free predators, the predator-induced phenotype survived more poorly and developed slowly, but this cost was apparently not associated with particular morphological traits. These results indicate that selection is currently promoting morphological plasticity in $R$. sylvatica, and support the hypothesis that plasticity represents an adaptation to variable predator environments.
\end{abstract}

(C) 1998 The Linnean Society of London

ADDITIONAL KEY WORDS:--inducible defence - morphology - natural selection predation.

\section{CONTENTS}

Introduction . . . . . . . . . . . . . . . . . . . . . . . 302

Methods . . . . . . . . . . . . . . . . . . . . . . . . 304

Plasticity experiment . . . . . . . . . . . . . . . . . . . 304

Predation trials: selection in the presence of Anax . . . . . . . . . . 306

'Correspondence to J. Van Buskirk. Present address: Institute of Zoology, University of Zürich, CH-8057 Zürich, Switzerland. Email: jvb@zool.unizh.ch 


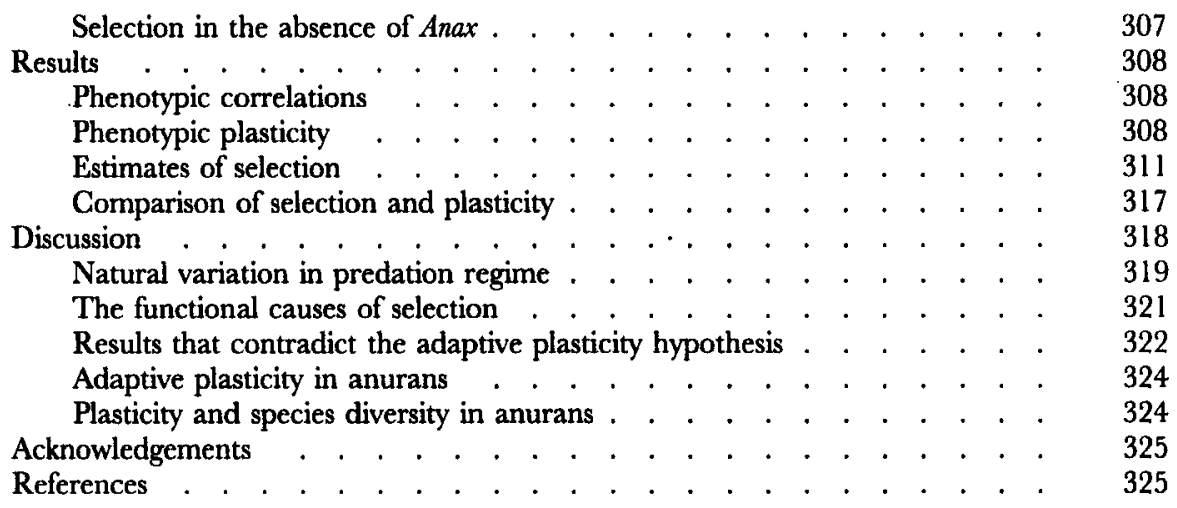

\section{INTRODUCTION}

The performance of an individual, and ultimately its fitness, results from complex relationships between the traits it possesses and the environment it occupies. Individuals with high relative fitness presumably have achieved an appropriate match between their phenotype and the environment. Most organisms achieve this match to some extent by selecting habitats at various scales, but they also match their phenotype to the environment by means of plasticity, in which individuals alter their phenotypes during development in response to environmental cues.

It has long been recognized that plasticity might represent an adaptation allowing individuals to match their phenotype to the local environment, given that reliable cues are available to signal the condition of the environment (Wright, 1931; Dobzhansky, 1951; Bradshaw, 1965; Levins, 1968; Stearns, 1989; West-Eberhard, 1989). This hypothesis constitutes an important and general conclusion of theoretical treatments of plasticity as well (Via \& Lande, 1985; Lively, 1986a; Gomulkiewicz \& Kirkpatrick, 1992; Moran, 1992; van Tienderen, 1997). Confirmation of the adaptive plasticity hypothesis (Schmitt, McCormac \& Smith, 1995). calls for evidence concerning both the present function of plasticity and the evolutionary forces that produced it in the past and presently maintain it (Williams, 1966; Lewontin, 1978; Brandon \& Rausher, 1996). Our goal is to assess one part of this hypothesis, the assumption that natural selection currently acts on plastic traits, and maintains plasticity by favouring different phenotypes in different environments.

To be convincing, a test of adaptation requires evidence in support of two central assumptions, neither of which implies that the other is true (Brandon \& Rausher, 1996). The first assumption is that the existing phenotype is optimal, at least locally. In the context of plasticity, this assumption implies that the average reaction norm within a population confers higher fitness than any alternative possible reaction norm. That is, the population should be at or near an evolutionary stable strategy that could not be invaded by genotypes displaying a different configuration or degree of plasticity. At this stage, predictions of the general form of the reaction norm may be constructed, based on knowledge of the functional consequences of phenotypic variation and the constraints operating within the system (Stearns, 1989; Werner \& Anholt, 1993; Smith \& Van Buskirk, 1995; Dudley \& Schmitt, 1996). Tests of these predictions typically compare the performance of the phenotype induced by an 
environment with the performance of other phenotypes induced by other environments. Many of these studies report that the phenotype that confers the highest performance within a particular environment is that which was induced by prior exposure to the environment (Harvell, 1986; Lively, 1986b; Spitze, 1992; McCollum \& Van Buskirk, 1996). This approach has not upheld the adaptive plasticity hypothesis in all cases, however (O'Brien et al., 1980; Baldwin, Sims \& Kean, 1990; Spitze, 1992; Schmitt, 1993; Kingsolver, 1995), reflecting extensive variability in performance or suggesting that constraints might often prevent organisms from evolving adaptive plasticity.

The second assumption of the adaptive plasticity hypothesis is that the reaction norm is a result of natural selection acting in the past. This is a primarily historical assumption, but it can be tested in at least two ways. First, phylogenetic tests of character evolution (Baum \& Larson, 1991; Leroi, Rose \& Lauder, 1994) can demonstrate an association between plasticity and environmental heterogeneity. The predicted outcome of such analyses is that taxa that routinely experience variable environments should display greater plasticity than taxa from constant environments, because only organisms exposed to multiple environments will undergo selection for plasticity. This prediction appears reasonable, but has not been uniformly upheld by empirical results (e.g. Semlitsch, Harris \& Wilbur, 1990; Galloway, 1995).

The assumption that a reaction norm resulted from natural selection can also be tested indirectly by measuring whether selection is currently maintaining plasticity. Such evidence would not demonstrate that selection in the past, across the existing set of environments, produced the reaction norm in the specific case, but it would help argue the general case that divergent selection produces phenotypic plasticity (Brandon \& Rausher, 1996). This is the approach we take in this study. We ask whether selection is currently acting to maintain plasticity, using a species that has an apparently adaptive morphological response to predators. If selection is currently maintaining plasticity, then it should be possible to show that there are differences among environments in the relationship between fitness and phenotype. A few earlier studies of plastic traits have demonstrated that selection currently favours different phenotypes in contrasting environments, and that the direction of selection is consistent with the adaptive plasticity hypothesis (Dudley \& Schmitt, 1996; Van Buskirk, McCollum \& Werner, 1997). If these results turn out to be general, then we will have strengthened the case that some types of plasticity evolve in response to divergent selection regimes in heterogeneous environments.

Amphibian larvae display extensive plasticity in life history, morphology, diet, and behaviour in response to variation in environmental conditions such as food, competitors, and predators (Skelly \& Werner, 1990; Newman, 1992; McCollum \& Van Buskirk, 1996). In many cases phenotypes are affected in such a way that plasticity appears to be beneficial, but specific assumptions of the adaptive plasticity hypothesis have not often been tested. For example, in ponds containing predatory insects, tadpoles of several species become relatively inactive and develop tail muscles and fins that are deep, broad, and sometimes brightly-coloured in comparison with those of tadpoles from predator-free habitats (Smith \& Van Buskirk, 1995; McCollum \& Van Buskirk, 1996). Each of these components of the phenotype that respond to the presence or absence of predators might contribute to an overall adaptive response to predators, because one can hypothesize functional connections between traits (e.g. behaviour, shape, colour) and individual performance with or without predators. However, it remains to be shown that the plastic traits are consistently beneficial 
when expressed in the appropriate environment (e.g. Anholt \& Werner, 1995; McCollum \& Van Buskirk, 1996), are targets of divergent selection across environments, or vary among species as predicted by the adaptive plasticity hypothesis.

We measured morphological plasticity and selection in tadpoles of the wood frog, Rana sylvatica (Anura: Ranidae), because this species occurs in ponds with highly variable predator faunas and the tadpoles show strong morphological and behavioural responses to predators. Rana sylvatica tadpoles exposed to dragonflies consistently have deeper tail fins and shorter bodies than tadpoles reared in the absence of predators. In this study, we ask whether selection on tadpole morphology, imposed by predatory dragonflies and competing tadpoles of a different species, is consistent with the hypothesis that plasticity in shape is maintained by divergent selection in the presence and absence of predators. Specifically, we predict that traits showing the most extensive plasticity also currently undergo the strongest selection, and that the directions of plasticity and selection are congruent.

\section{METHODS}

We collected Rana sylvatica eggs in early April 1996 from eight populations on and near the University of Michigan's E.S. George Reserve in southeastern Michigan, USA. Three clutches of full-sibs were taken from each population, and the clutches were maintained separately in well water within $300-\mathrm{L}$ outdoor wading pools until the experiment began, 19-21 days after the tadpoles hatched. The populations came from fish-free temporary or semi-permanent ponds, including four open marshes and four closed-canopy woodland ponds. The choice of populations and clutches was dictated by the design of a separate experiment (R.A. Relyea, unpublished).

The study consisted of three phases. First we reared the tadpoles in the presence or absence of caged dragonfly larvae for several weeks in order to estimate morphological plasticity. Then we took tadpoles from the two environments and subjected them to free dragonflies in overnight predation trials to determine whether predators killed tadpoles non-randomly with respect to body size and shape. Finally, we estimated selection in the absence of free predators by comparing tadpole phenotypes with tadpole performance in cattle tanks over the entire larval period, and by relating growth rate to morphology in a laboratory competition experiment.

\section{Plasticity experiment}

The plasticity experiment was conducted in outdoor artificial ponds (plastic stock tanks). Tadpoles do well in the semi-natural conditions of these ponds, which are large enough to support a sufficient number of tadpoles for predation trials. We filled the tanks with well water on 24-26 April 1996 to a depth of $41 \mathrm{~cm}(1100 \mathrm{~L}$ volume, $2.6 \mathrm{~m}^{2}$ surface area), and stocked them with $0.3 \mathrm{~kg}$ oak leaf litter, aliquots of phytoplankton and zooplankton collected from nearby ponds, and $25 \mathrm{~g}$ commercial rabbit chow to provide an initial nutrient source for the food web. Tanks were kept covered with lids constructed of fibreglass windowscreen to prevent colonization by unwanted predators and amphibians. We introduced 110 tadpoles to each tank on 6 May 1996 (42 individuals $\left./ \mathrm{m}^{2}\right)$. 
The experiment included 24 replicates of two treatments, Anax present or no predators present, with each replicate comprised of 110 full sibs from one of the eight source populations. The treatments were assigned at random to 48 tanks arranged in an hexagonal array in an open field at the George Reserve. Four lateinstar Anax longipes were placed within each of the Anax tanks, confined inside floating cages constructed of a $12 \mathrm{~cm}$ length of plastic drainpipe $(11 \mathrm{~cm}$ diameter) with the ends covered by fibreglass windowscreening. Tanks in the no-predator treatment contained four empty cages. Each Anax was fed 4-7 R. sylvatica tadpoles (300 mg total), three times per week, throughout the experiment.

Groups of tadpoles were removed from the tanks after 18 days for predation trials and estimates of plasticity (see below), after 23 days for a competition experiment (see below), after 35 days for a sample of growth rate (20 tadpoles weighed to the nearest $\mathrm{mg}$ ), and for unrelated experiments on one other occasion. In all cases, the same number of individuals was removed from every tank.

Once metamorphosis was underway we collected all metamorphosing froglets from the tanks 3-5 times per week, and recorded the date upon which each one resorbed its tail (stage 46; Gosner, 1960). For each tank we determined the average date of metamorphosis, and calculated survival to metamorphosis as the number of froglets divided by 30 (the number of tadpoles not removed for ancillary experiments during the course of the study).

There were no significant differences among populations in the impact of selection, and we will hereafter disregard the population of origin and treat each clutch as an independent replicate. Population-level differences in phenotype and plasticity will be reported elsewhere (R.A. Relyea, unpublished).

We measured the morphology of tadpoles using a dissecting scope and camera connected to a computer equipped with image analysis software. Viewing the tadpole from the side we digitized the length and depth of the body, maximum depth of the tail fin, maximum tail muscle depth at the base of the tail, and the tail length measured from the junction of the spinal column and the body. Viewing from the top we digitized body width and maximum width of the tail muscle at the base. To generate a measure of overall body size, we performed a principal component analysis on the correlation matrix constructed from five of these log-transformed linear measures (excluding width and depth of the tail muscle because they scale less reliably with body size) and the wet mass of the preserved tadpole, and kept the first component (which accounted for $90 \%$ of the total variance) as a measure of size for subsequent analyses.

Correlations among traits present a problem for interpreting estimates of plasticity and selection because they potentially obscure the traits which are actually exhibiting plasticity or undergoing selection. Phenotypic correlations can generate indirect selection, in which selection acting on one trait causes apparent selection on correlated traits (Falconer \& Mackay, 1996). The ambiguity is less problematic in the context of plasticity, but knowledge of correlations among traits can indicate the extent to which changes in several traits actually represent the plastic response of a single multidimensional trait. We therefore began our analysis by testing for individual-level phenotypic correlations among all combinations of traits, separately for the two treatments (caged Anax and no-predators). We focused on four measures of tail shape and three measures of body shape, which were the residuals of logtransformed tail length, tail fin depth, tail muscle depth, tail muscle width, body length, body depth, and body width after regression against the first principal 
component. Our method of standardizing measures of shape by regression against a single size component, termed shearing, is a common preliminary step in morphometric analysis (Bookstein, 1991).

We tested the significance of plasticity by comparing the morphology of tadpoles from the no-predator and caged-Anax tanks; phenotypes within each tank were estimated from the average of 10 tadpoles collected at day 18. First we performed a multivariate analysis of variance (MANOVA) testing for differences between treatments in the seven measures of shape. The dominant eigenvector for the tank treatment effect in the MANOVA represented the pattern of plasticity exhibited by all traits together, after accounting for correlations among traits. This vector is the linear combination of the seven response traits that distinguished most clearly between tadpoles originating from the two environments; thus it defines the principal phenotypic axis along which plasticity was expressed. We also inspected univariate ANOVAs to reveal how each trait responded to the difference between tank treatments when viewed in isolation.

\section{Predation trials: selection in the presence of Anax}

We measured selection imposed by dragonfly predation on $R$. sylvatica by comparing the morphology of tadpoles which survived exposure to free-ranging Anax in shortterm predation trials with that of tadpoles exposed to no predators during the same time period. Eighteen days after starting the plasticity experiment, we removed 20 tadpoles from each tank, haphazardly divided them into two groups of 10 , and placed each group into a plastic tub (10L water; $26 \times 38 \times 14 \mathrm{~cm})$. The tubs contained a coil of plastic rope to provide perches for the predator, and were shelved in an indoor laboratory at a cycle of 14:10 hr light:dark. The experiment had two treatments (presence or absence of the predator, Anax), which were performed for tadpoles from each tank in the plasticity experiment, making 96 total tubs. A single final-instar Anax longipes, which had been starved for 2 days before the experiment, was introduced to the appropriate tubs at 17:00 on 24 May 1996. The predators were removed the following day at 12:00, and all surviving tadpoles were preserved in $10 \%$ formalin.

We tested for selection on morphology in the presence of predators by determining whether dragonflies killed tadpoles non-randomly with respect to body size and the seven measures of body shape. The average values of these traits for the 10 tadpoles that were not exposed to predators provided an estimate of phenotype prior to selection, and the averages for those tadpoles that survived Anax predation provided an estimate of phenotype after selection. For each cattle tank we determined the selection differential for each trait as the trait value after selection minus the trait value before selection. Selection differentials were standardized by dividing this difference by the phenotypic standard deviation before selection (Arnold \& Wade, 1984). The resulting standardized selection differential is often called the 'selection intensity' (Falconer \& Mackay, 1996).

We tested the significance of selection differentials imposed by Anax predation using a linear model that included tank treatment and intercept in the design matrix. The intercept tested whether the grand mean of the selection intensities was different from zero (that is, whether there was significant selection averaged across both phenotypes). The treatment effect tested whether the magnitude of the selection 
intensities depended on prior exposure to either Anax or no predators in the tanks. We began with a multivariate analysis on selection intensities for all seven tail and body traits together, to determine whether there was significant selection on overall shape. As above, the dominant eigenvector for the intercept term in MANOVA reflected the pattern of selection acting on the entire suite of correlated traits. In this case, the eigenvector contained the linear combination of the seven response variables (selection intensities) that deviated most strongly from zero, which defined the phenotypic axis along which selection acted after accounting for phenotypic correlations. We also inspected univariate ANOVAs to reveal the apparent direction and magnitude of selection acting on each trait, disregarding the correlations among traits.

\section{Selection in the absence of Anax}

The hypothesis of divergent selection across environments predicts that traits associated with higher performance in the absence of predators should be opposite to those that confer higher survival in the predation trials. We used two approaches to check for selection on tadpole morphology in the absence of predators. First, we performed a short-term laboratory experiment to determine if individual growth rate was related to morphology, in both the presence and absence of a competing species. Measuring selection under conditions of food limitation is realistic in light of the natural history of Rana sylzatica, since tadpoles in predator-free ponds occur very often at densities that are high enough for competition to be important (E.E. Werner et al., unpublished).

The competition trial began 5 days after the predation trial, when the cattle tank experiment had been underway for 23 days. We collected 20 tadpoles from each tank, haphazardly divided them into two groups of 10 individuals each, and placed each group into an 8-L plastic tub on a laboratory shelf (96 tubs in total). Half of the tubs contained a single Anax larva, because the predator environment established in the cattle tank experiment was maintained during the competition trial. Dragonflies were confined within a small plastic cup with a screened lid, and were fed two $R$. syluatica tadpoles $(\sim 300 \mathrm{mg})$ every other day. The tadpoles from each tank were exposed to two treatments, consisting of the presence or absence of 3 second-year bullfrog tadpoles (Rana catesbeiana, average individual mass $=3.35 \mathrm{~g}$ ), chosen because they show no behavioural response to Anax at such large sizes (Peacor \& Werner, 1997). We weighed the 96 sets of 10 tadpoles just before placing them in the tubs, and fed them every day during the trial. For the first 3 days we added $10 \%$ of the average body mass of the $R$. sylvatica tadpoles per day (3:1 mixture of rabbit chow: Tetramin fish flakes), but this ration proved to be too high, causing excessive bacterial growth. We therefore changed the water and reduced the daily ration to $5 \%$ of body mass. The experiment ended after 7 days, at which time all survivors were weighed. Our analysis compared the growth of the 10 tadpoles within each tub (proportional change in mass) with their average morphological trait values measured at 18 days. Multiple regressions were performed on growth in the presence and absence of competitors, as well as the difference in growth between the two competitor treatments, which we interpret as an estimate of the impact of competition.

Our second approach to estimating selection without predators was a comparative analysis of tadpole performance in the absence of free-ranging predators within the 
plasticity experiment. We began with a multivariate multiple regression testing for a relationship between performance and tadpole phenotypes within all 48 cattle tanks, since none contained free-ranging predators. The three performance measures were growth [log(mass on day 35/initial mass)], survival to metamorphosis, and average time to metamorphosis; the model included the predator treatment (Anax present or absent) and the seven morphological traits (measured at day 18). We also examined univariate relationships between the three performance measures and phenotype. Tank means were the unit of analysis, because survival is a collective variable and we have no data on individual phenotypes late in the experiment. Predator treatment was included in the model to account for variation in growth or survival due to plastic responses to predators, before asking whether populations of tadpoles having different average phenotypes performed differently.

Both of our tests for selection in predator-free environments assume that survival, body size, and timing of metamorphosis are correlated with fitness, which is supported by field data from several amphibian species (Smith, 1987; Semlitsch, Scott \& Pechmann, 1988; Berven 1990; Scott, 1994).

\section{RESULTS}

\section{Phenotypic correlations}

There were strong phenotypic correlations among measures of body shape and size of Rana syluatica tadpoles in both environments after 18 days (Table 1). All four measures of tail shape were positively correlated with one another, the three measures of body shape were positively correlated, and all body traits were negatively correlated with tail traits. The congruence between matrices measured in the two environments was highly significant $(P<0.0001$, Mantel randomization test; Mantel, 1967), indicating that the pattern of phenotypic correlation was similar in the presence and absence of dragonflies. These results indicate that our measures of body and tail shape do not represent independent traits, presumably because they share some level of underlying genetic or developmental causation. This confirms that multivariate measures of plasticity and selection are appropriate.

\section{Phenotypic plasticity}

Rana sylvatica displayed dramatic plasticity in body and tail shape at 18 days. Tadpoles from the two environments differed most strongly in their body length and tail fin depth, relative to overall body size, according to the dominant eigenvector derived from MANOVA on all seven traits (Table 2A). In comparison with tadpoles reared in predator-free ponds, those exposed to Anax had relatively short bodies and long, deep tails. Univariate analyses suggested that predator-induced tadpoles were smaller, had shorter and narrower bodies, deeper tail fins, and marginally longer tails (Fig. 1A, B, Table 2B), and variation in tail muscle shape across predator environments was not significant (Fig. 1C). There were minor differences between the multivariate and univariate depictions of plasticity, resulting from correlations among the traits that responded to predators. For example, when viewed in isolation, 
Table 1. Phenotypic correlations among measures of size and shape in Rana sylvatica tadpoles. Estimates are based on 233 individuals sampled in the nopredator environment (above the diagonal) and 230 sampled in the Anax environment (below the diagonal), on day 18 . Body size was the first component from a PCA; all other traits are residuals on PCl. Boldfaced values are significant: $P<0.05$ if $r>0.121, P<0.01$ if $r>0.150$

\begin{tabular}{|c|c|c|c|c|c|c|c|c|}
\hline \multirow[b]{2}{*}{ Trait } & \multicolumn{8}{|c|}{ Trait } \\
\hline & $\begin{array}{l}\text { Body } \\
\text { size }\end{array}$ & $\begin{array}{l}\text { Body } \\
\text { length }\end{array}$ & $\begin{array}{l}\text { Body } \\
\text { depth }\end{array}$ & $\begin{array}{l}\text { Body } \\
\text { width }\end{array}$ & $\begin{array}{c}\text { Tail } \\
\text { length }\end{array}$ & $\begin{array}{l}\text { Tail fin } \\
\text { depth }\end{array}$ & $\begin{array}{l}\text { Muscle } \\
\text { depth }\end{array}$ & $\begin{array}{l}\text { Muscle } \\
\text { width }\end{array}$ \\
\hline Body size & - & $-0.486^{*}$ & -0.177 & $-0.307^{*}$ & 0.200 & $0.540^{*}$ & 0.253 & 0.158 \\
\hline Body length & $-0.719^{*}$ & - & 0.164 & $0.212^{*}$ & $-0.402^{*}$ & $-0.541^{*}$ & $-0.320^{*}$ & $-0.228^{*}$ \\
\hline Body depth & -0.132 & 0.051 & - & $0.420^{*}$ & $-0.600^{*}$ & -0.537 & $-0.462^{*}$ & -0.133 \\
\hline Body width & $-0.215^{*}$ & 0.104 & $0.473^{*}$ & - & $-0.646^{*}$ & $-0.577^{*}$ & $-0.287^{*}$ & $-0.215^{*}$ \\
\hline Tail length & -0.120 & $-0.227^{*}$ & $-0.580^{*}$ & $-0.705^{*}$ & - & $0.235^{*}$ & $0.282^{*}$ & 0.020 \\
\hline Tail fin depth & $0.676^{*}$ & $-0.627^{*}$ & $-0.471^{*}$ & $-0.456^{*}$ & 0.136 & - & $0.386^{*}$ & 0.105 \\
\hline Tail muscle depth & 0.101 & $-0.212^{*}$ & $-0.401^{*}$ & $-0.285^{*}$ & $0.305^{*}$ & $0.423^{*}$ & - & $0.289^{*}$ \\
\hline Tail muscle width & -0.045 & -0.005 & -0.133 & -0.097 & 0.095 & $0.276^{*}$ & 0.322 & - \\
\hline
\end{tabular}


TABLE 2. Multivariate and univariate analyses of plasticity in Rana syluatica tadpoles. Morphology was measured after 18 days exposure to environments having either caged Anax larvae or no predators. The dominant eigenvector represents the linear combination of traits that differed most strongly between predator treatments; traits with negative coefficients were larger in the Anax treatment

\begin{tabular}{|c|c|c|c|c|c|c|c|c|c|c|}
\hline \multicolumn{11}{|c|}{ A. MANOVA: plasticity in seven measures of tadpole shape } \\
\hline Source & df & Wilks' $F$ & $P$ & $\begin{array}{l}\text { Body } \\
\text { length }\end{array}$ & $\begin{array}{l}\text { Body } \\
\text { depth }\end{array}$ & $\begin{array}{l}\text { Body } \\
\text { width }\end{array}$ & $\begin{array}{c}\text { Tail } \\
\text { length }\end{array}$ & $\begin{array}{c}\text { Tail fin } \\
\text { depth }\end{array}$ & $\begin{array}{c}\text { Muscle } \\
\text { depth }\end{array}$ & $\begin{array}{c}\text { Muscle } \\
\text { width }\end{array}$ \\
\hline Tank Environment & 7,40 & 11.69 & 0.0001 & 3.420 & -1.100 & -1.249 & -1.636 & -3.676 & 0.757 & 0.601 \\
\hline
\end{tabular}

B. Univariate ANOVA: plasticity in separate traits

\begin{tabular}{lcccc} 
Response & $\begin{array}{c}\text { Model SS } \\
(1 \mathrm{df})\end{array}$ & $\begin{array}{c}\text { Error } \\
\text { SS (46 df) }\end{array}$ & \multicolumn{1}{c}{$\boldsymbol{F}$} & $P$ \\
\hline Size (PC1) & 95.3 & 71.73 & 61.1 & 0.0001 \\
Body length & 0.029 & 0.018 & 75.18 & 0.0001 \\
Body depth & 0.003 & 0.017 & 7.48 & 0.0088 \\
Body width & 0.001 & 0.011 & 3.63 & 0.0631 \\
Tail length & 0.003 & 0.032 & 3.97 & 0.0524 \\
Tail fin depth & 0.058 & 0.042 & 63.29 & 0.0001 \\
Muscle depth & 0.002 & 0.049 & 2.34 & 0.1329 \\
Muscle width & 0.0005 & 0.085 & 0.29 & 0.5959 \\
\hline
\end{tabular}



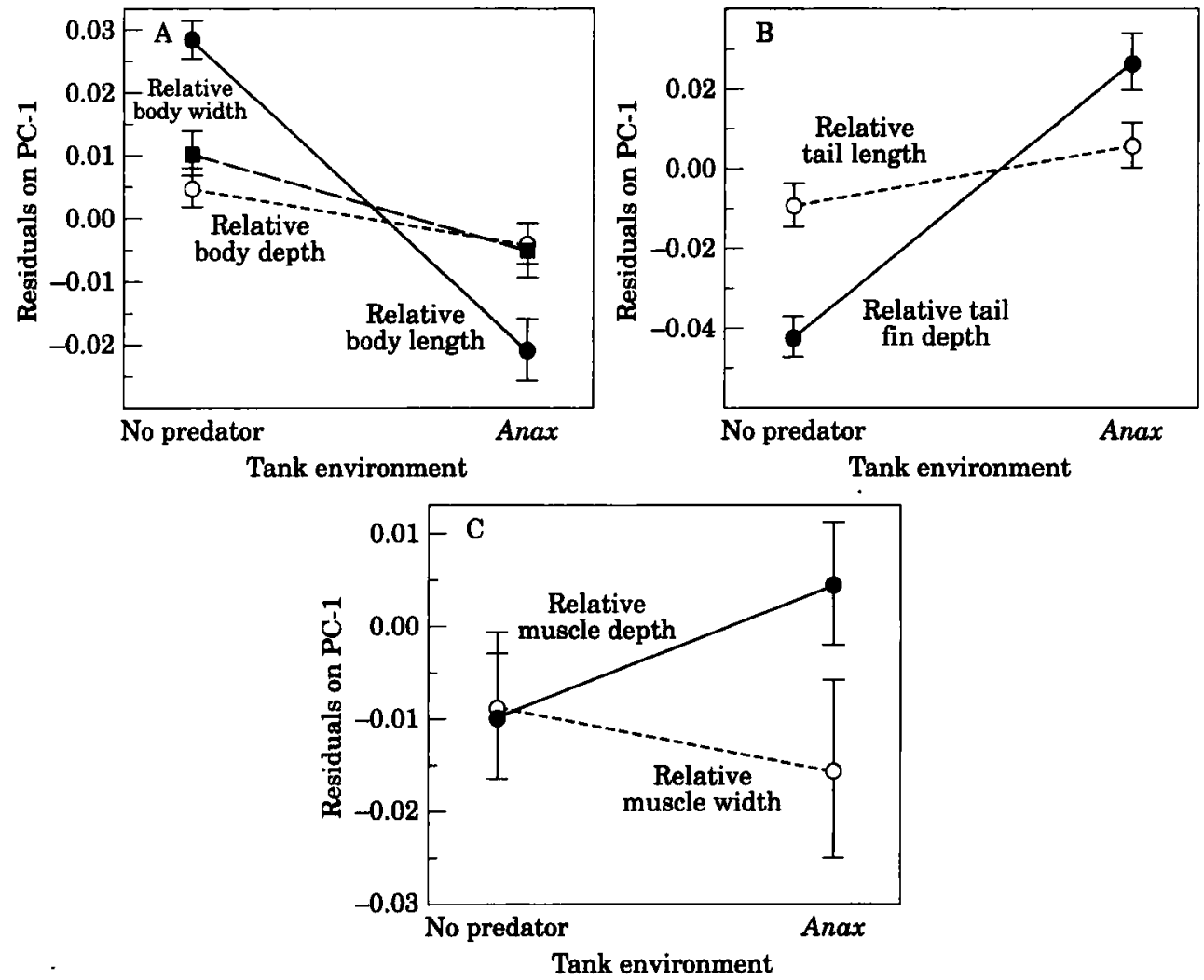

Figure 1. Plastic morphological responses of Rana sylvatica tadpoles after 18 days in artificial ponds containing either caged Anax dragonflies or no predators. All responses are corrected for body size by first regressing against $P C 1$ and retaining the residuals for subsequent analysis. Shown are means \pm 1 SE, calculated from univariate comparisons between treatments, with 24 replicates. (A) body shape; (B) tail fin shape; (C) tail muscle shape.

relative tail muscle depth increased slightly when Anax was present (Fig. 1A), whereas the same trait showed a decrease in the multivariate analysis (Table 2A). The increase in muscle depth apparent in the univariate comparison may have arisen because of its negative correlation with body length (Table 1).

\section{Estimates of selection}

In the overnight predation trials, dragonflies killed an average of $3.0 \pm 0.4$ tadpoles from the Anax treatment and 2.0 \pm 0.3 tadpoles from the no-predator treatment (mean $\pm 1 \mathrm{SE} ; P=0.029, t$-test). The fact that tadpoles having the predator-induced phenotype did not experience enhanced survival in this experiment, as in some others (e.g. McCollum \& Van Buskirk, 1996), presumably resulted from their smaller body size (Table $2 \mathrm{~B})$. 

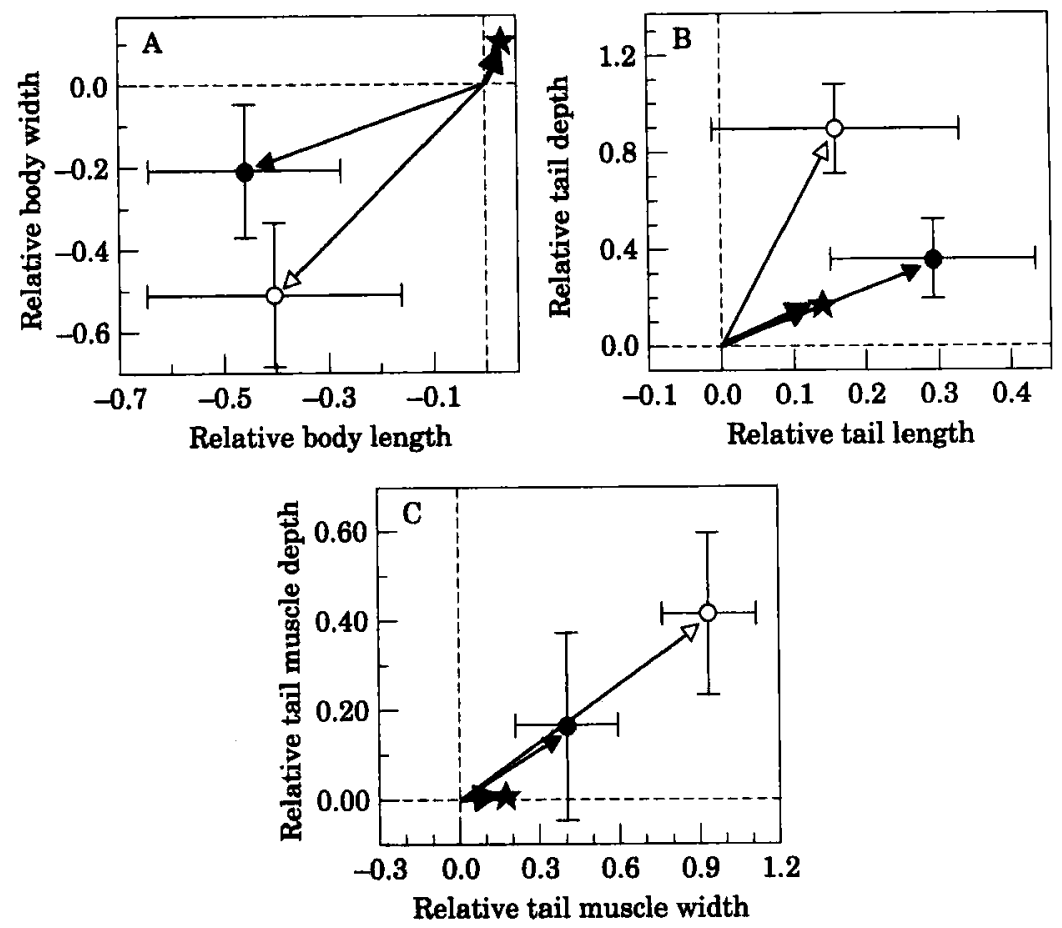

Figure 2. Standardized selection differentials (in units of standard deviation of the trait prior to selection) on (A) body, (B) tail fin and (C) tail muscle shape imposed by Anax preying on Rana sylvatica tadpoles. The two phenotypes were induced by exposure to caged dragonflies or no predators in artificial ponds for 18 days. The heavy arrows and the $\star$ depict the direction and magnitude of direct selection acting on both phenotypes, estimated by the coefficients of the dominant eigenvector in MANOVA on seven traits. Circular symbols $( \pm 1 \mathrm{SE})$ represent selection coefficients estimated from univariate analyses, and therefore result in part from indirect selection acting on other traits. Dashed lines indicate selection differentials of zero, as expected if no selection is acting on the trait. (O) nopredator phenotype; $(\mathcal{O})$ predator-induced phenotype.

Predation by Anax imposed strong selection on tadpole shape, and the magnitude of selection was similar for both the predator-induced phenotype and the no-predator phenotype (Fig. 2, Table 3). Multivariate and univariate estimates of selection intensity were quite different, as expected when selection acts on highly correlated traits. The significant intercept term in the MANOVA (which tests for selection across both tank treatments) resulted from selection favouring tadpoles with relatively deep tail fins and large tail muscles in the presence of predators, although all seven traits were under positive selection to some degree (Table 3A). In contrast, standardized selection differentials calculated from univariate comparisons revealed selection for smaller body dimensions and larger tail dimensions (Table 3B, Fig. 2). There was no selection on body size (PC1). Figure 2 makes clear that the univariate and multivariate approaches yielded similar estimates for selection on the tail, but very different results for body length and body width. These results suggest that the tail fin and tail muscle were under direct selection for increasing values, while the body measures were under indirect selection mediated through their negative correlation with tail traits. 
TABLE 3. Analyses of selection by dragonflies on Rana sylvatica morphology. Selection differentials were divided by the SD of the trait prior to selection. The intercept tests whether selection intensity differed from zero (i.e. tests for selection); the tank environment term tests whether selection intensities for the two phenotypes differed in magnitude. The dominant eigenvector represents the linear combination of traits most strongly aligned with the source of variation; traits with negative values (for the intercept) underwent increasing selection, or (for tank environment) showed stronger increasing selection in the no-predator

treatment. Entries for univariate analyses give $F$ (above) and $P$-value (below)

A. MANOVA: selection on seven measures of tadpole shape

Coefficients of the dominant eigenvector

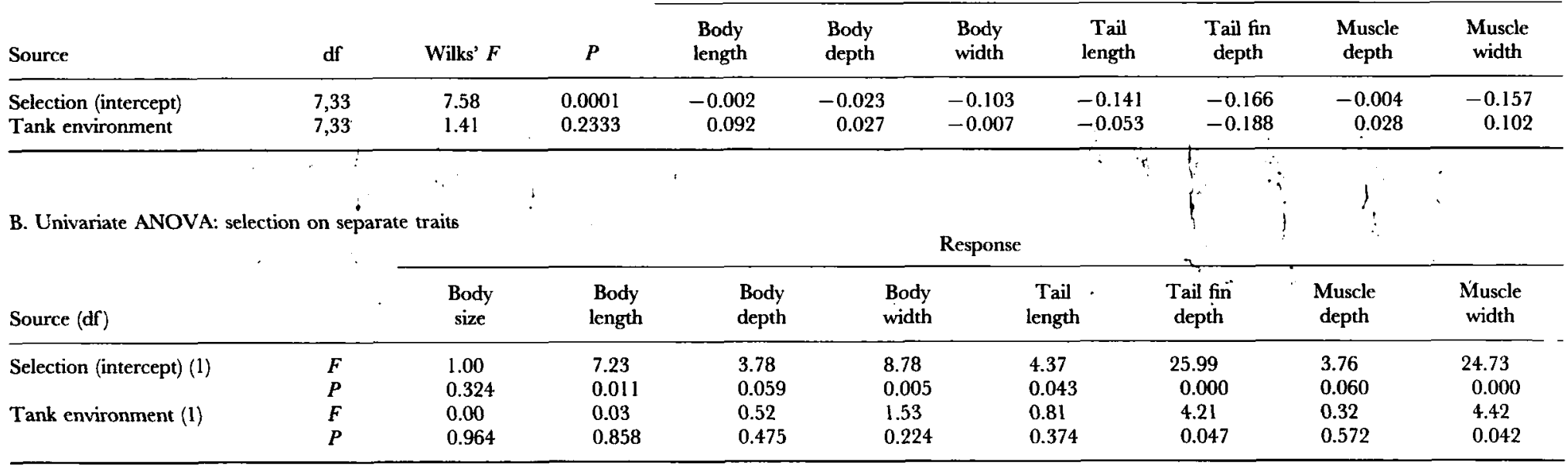




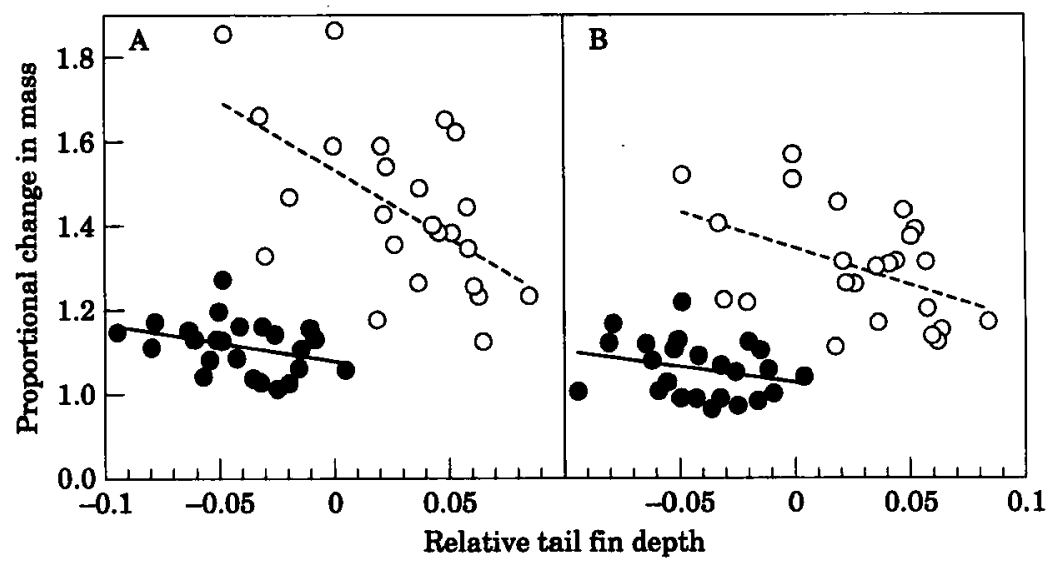

Figure 3. Growth rates of groups of 10 Rana sylvatica tadpoles, measured over 7 days in the (A) absence and (B) presence of competing $R$. catesbeiana. Growth rate declined with increasing tail fin depth, especially in the treatment without competitors and for tadpoles originating from tanks with caged dragonflies. Predator-induced tadpoles grew relatively more during the experiment, probably because of their small initial size. (O) no-predator phenotype; $(O)$ predator-induced phenotype.

Our two tests for selection in the absence of predators yielded mixed results. The competition trials provided convincing evidence for selection acting against tadpoles with deep tail fins. Size-specific growth rate was higher for the predator-induced tadpoles than for no-predator tadpoles (Fig. 3, Table 4), probably because they were smaller at the beginning of the trials and therefore received more food in proportion to their mass. Tail fin depth (Fig. 3) and body depth were negatively related to growth in both the presence and absence of predators: tadpoles with deep bodies and deep tails grew relatively slowly. Also, introducing competitors reduced the growth rate of all tadpoles, but the reduction was significantly greater for the Anax treatment than for the no-predator treatment (Table 4, 9.1\% decrease in growth for predator-induced tadpoles versus $4.4 \%$ decrease for no-predator tadpoles). Although the impact of competition was not related to any morphological trait within tank treatments (Table 4), the experiment as a whole suggests that some traits favoured in environments with predators lead to reduced growth rates, and that predator-induced tadpoles may be more sensitive to competition.

In contrast with the results of the competition trials, there was no consistent evidence of selection on tadpole morphology in the absence of free predators in the outdoor tanks. None of the measures of shape at day 18 was significant in a multivariate analysis on survival, growth to 35 days, and average time to metamorphosis (all $P>0.15$ ). The predator treatment strongly influenced performance because tadpoles exposed to caged Anax survived slightly worse ( $83.6 \%$ versus $85.2 \%$ ) and had a longer larval period ( $57.0 \mathrm{~d}$ versus 50.8$)$ than did tadpoles in predatorfree tanks (Wilks' $F_{3,37}=19.5, P=0.0001$ ). Separate multiple regressions on the three measures of performance confirmed the weak relationship between phenotypic traits and the three correlates of fitness (Table 5). We conclude that the predator-induced phenotype performs more poorly than the no-predator phenotype in ponds without free-ranging predators, but that selection on tadpole morphology in these ponds may be weak or difficult to detect using the aggregate measures of performance and phenotype available here. 
TABLE 4. Multiple regressions for the relationship between tadpole morphology and growth in the competition trials. Growth [log(final mass/initial mass)] of $R$. sylvatica tadpoles from tanks with and without predators was measured in the presence and absence of 3 Rana catesbeiana tadpoles (competitors). The impact of competitors is the proportional decline in growth in the presence of $R$. catesbeiana. Entries in the table are the regression coefficient (top), $F$-value (middle), and $P$-value (bottom). A positive coefficient indicates that tadpoles which possessed a relatively large value of the trait grew fast or were less negatively affected

\begin{tabular}{|c|c|c|c|c|c|c|c|c|c|}
\hline \multirow[b]{2}{*}{ Response } & & \multicolumn{8}{|c|}{ Source of variation } \\
\hline & & $\begin{array}{c}\text { Tank } \\
\text { treatment }\end{array}$ & $\begin{array}{c}\text { Relative } \\
\text { body length }\end{array}$ & $\begin{array}{c}\text { Relative } \\
\text { body depth }\end{array}$ & $\begin{array}{c}\text { Relative } \\
\text { body width }\end{array}$ & $\begin{array}{l}\text { Relative } \\
\text { tail length }\end{array}$ & $\begin{array}{l}\text { Relative tail } \\
\text { fin depth }\end{array}$ & $\begin{array}{l}\text { Relative tail } \\
\text { muscle depth }\end{array}$ & $\begin{array}{l}\text { Relative tail } \\
\text { muscle width }\end{array}$ \\
\hline \multirow{4}{*}{$\begin{array}{l}\text { Growth with no } \\
\text { competitors }\end{array}$} & & & & & & & & & \\
\hline & $\beta$ & - & -1.27 & -2.69 & -1.72 & -1.68 & -2.62 & 0.15 & 0.21 \\
\hline & $F$ & 92.66 & 1.31 & 4.32 & 2.11 & 2.96 & 7.58 & 0.19 & 1:02 \\
\hline & $P$ & 0.0001 & 0.2598 & 0.0442 & 0.1544 & 0.0935 & 0.0089 & 0.6643 & 0.3184 \\
\hline \multirow{4}{*}{$\begin{array}{l}\text { Growth with } \\
\text { competitors }\end{array}$} & & & & & & & & & \\
\hline & $\beta$ & - & -0.91 & -1.96 & -0.58 & -0.87 & -1.52 & -0.23 & 0.35 \\
\hline & $F$ & 62.44 & 0.97 & 3.25 & 0.34 & 1.13 & 3.63 & 0.64 & 3.98 \\
\hline & $P$ & 0.0001 & 0.3310 & 0.0790 & $\quad 0.5647$ & 0.2944 & 0.0640 & 0.4292 & 0.0532 \\
\hline \multirow{4}{*}{$\begin{array}{l}\text { Proportional impact } \\
\text { of competitors }\end{array}$} & & & & & & & & & \\
\hline & $\beta$ & - & 0.47 & 1.04 & 1.71 & 1.27 & 1.58 & 0.60 & 0.26 \\
\hline & $F$ & 18.62 & 0.18 & 0.65 & 2.09 & 1.70 & 2.74 & 3.18 & 1.54 \\
\hline & $P$ & 0.0001 & 0.6746 & 0.4267 & 0.1563 & 0.2005 & 0.1061 & 0.0825 & 0.2216 \\
\hline
\end{tabular}


TABLE 5 Multiple regressions for the relationship between tadpole morphology and performance in the plasticity experiment. Entries in the table are the regression coefficient (top), $F$-value (middle), and $P$-value (bottom). A positive coefficient indicates that tanks in which tadpoles possessed a relatively large value of the trait also scored high values on the performance measure. There is no consistent evidence for a relationship between phenotype and performance in tanks with no free predators

\begin{tabular}{|c|c|c|c|c|c|c|c|c|c|}
\hline \multirow[b]{2}{*}{ Response } & & \multicolumn{8}{|c|}{ Source of variation } \\
\hline & & $\begin{array}{c}\text { Tank } \\
\text { treatment }\end{array}$ & $\begin{array}{c}\text { Relative } \\
\text { body length }\end{array}$ & $\begin{array}{c}\text { Relative } \\
\text { body depth }\end{array}$ & $\begin{array}{c}\text { Relative } \\
\text { body width }\end{array}$ & $\begin{array}{c}\text { Relative } \\
\text { tail length }\end{array}$ & $\begin{array}{l}\text { Relative tail } \\
\text { fin depth }\end{array}$ & $\begin{array}{l}\text { Relative tail } \\
\text { muscle depth }\end{array}$ & $\begin{array}{l}\text { Relative tail } \\
\text { muscle width }\end{array}$ \\
\hline \multirow[t]{3}{*}{ Growth to 35 days } & $\beta$ & - & 0.171 & 0.099 & 0.089 & $0.06 \mathrm{I}$ & 0.041 & 0.022 & -0.004 \\
\hline & $F$ & 2.74 & 2.76 & 0.69 & 0.66 & 0.44 & 0.21 & 0.49 & 0.04 \\
\hline & $P$ & 0.1059 & 0.1047 & 0.4127 & 0.4224 & 0.5093 & 0.6462 & 0.4885 & 0.8400 \\
\hline \multirow{4}{*}{$\begin{array}{l}\text { Survival to } \\
\text { metamorphosis }\end{array}$} & & & & & & & & & \\
\hline & $\beta$ & - & -0.142 & 1.843 & -0.346 & 0.286 & 1.765 & 0.277 & -0.072 \\
\hline & $F$ & 4.91 & 0.00 & 0.25 & 0.01 & 0.01 & 0.42 & 0.08 & 0.02 \\
\hline & $P$ & 0.0327 & 0.9645 & 0.6210 & 0.9189 & 0.9189 & 0.5201 & 0.7759 & 0.9029 \\
\hline \multirow{4}{*}{$\begin{array}{l}\text { Time to } \\
\text { metamorphosis }\end{array}$} & & & & & & & & & \\
\hline & $\beta$ & - & -0.304 & -1.284 & 0.063 & 0.044 & 0.789 & 0.080 & 0.386 \\
\hline & $F$ & 58.09 & 0.12 & 1.61 & 0.00 & 0.00 & 1.12 & 0.09 & 5.69 \\
\hline & $P$ & 0.0001 & 0.7273 & 0.2127 & 0.9460 & 0.9547 & 0.2961 & 0.7654 & 0.0220 \\
\hline
\end{tabular}



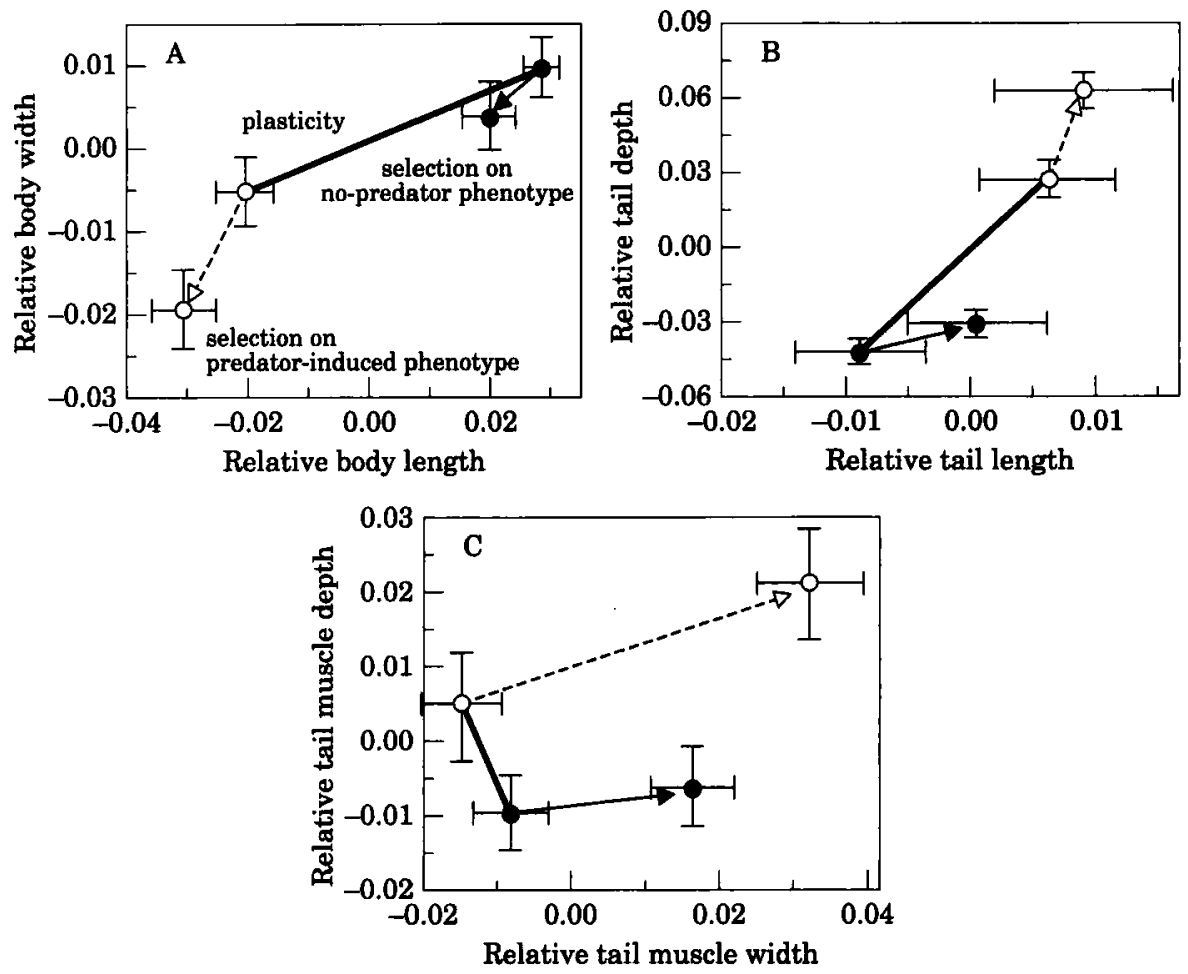

Figure 4. Phenotypic plasticity and selection on (A) body (B) tail fin and (C) tail muscle shape of Rana syluatica tadpoles. The heavy line represents plasticity, which was measured by exposing tadpoles to environments with either caged Anax or no predators for 18 days. The arrows represent selection differentials, measured as the change in mean phenotype during overnight predation trials with free Anax (dashed arrow = predator-induced tadpoles; solid arrow $=$ no-predator tadpoles). Both plasticity and selection values were taken from univariate comparisons. Selection on body shape and tail fin shape was consistent with the adaptive plasticity hypothesis. $(O)$ no-predator phenotype; $(O)$ predatorinduced phenotype.

\section{Comparison of selection and plasticity}

The hypothesis that plasticity represents an adaptation to environmental variability predicts that traits which show the greatest plasticity are also under the strongest selection. Univariate estimates from our predation trials support this prediction. Bivariate plots of body and tail shape measurements illustrate that plastic responses to predators in cattle tanks were closely aligned with natural selection imposed by dragonfly predation (Fig. 4A, B), but this was not true for tail muscle shape (Fig. 4C). Body length and tail depth showed the strongest plasticity, and these two traits also underwent strong selection in these univariate contrasts. The only variable that departed strongly from the expected pattern was tail muscle width, which was slightly smaller in the presence of Anax, but was the target of strong positive selection in the predation trials.

Selection tended to favour opposite values of traits in the predation and competition trials. For this comparison we used coefficients derived from multivariate analyses of plasticity and selection, because they incorporate information about correlations 


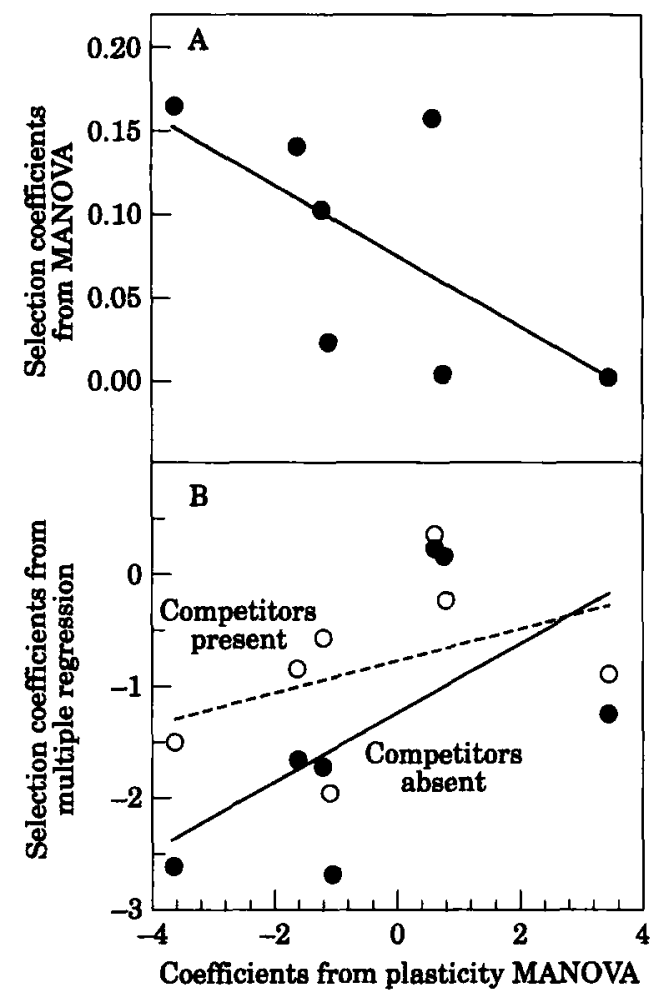

Figure 5. Relationship between morphological plasticity and selection in experiments with predators and competitors, for seven measures of shape in Rana sylvatica tadpoles. Coefficients reflect the strength of plasticity or selection on each trait, and are derived from multivariate analyses that adjust for phenotypic correlations among traits. Plasticity coefficients are the elements of the dominant eigenvector from MANOVA on phenotypes in the cattle tank experiment (Table 2A); traits with positive values were larger in the no-predator environment. Selection coefficients in the presence of Anax (A) are the elements of the dominant eigenvector from MANOVA testing for selection in predation trials (Table $3 \mathrm{~A}$; coefficients multiplied by -1 so that positive values indicate selection favouring large trait values). There was a significant correlation between selection by dragonflies and plasticity $\left(r_{1}=-0.79, P=\right.$ $0.036)$. For the growth experiment (B), coefficients are from multiple regression predicting growth rate from morphology (Table 4), shown separately for tadpoles in the presence and absence of competing $R$. catesbeiana. Traits that were relatively large in the presence of Anax were associated with reduced growth in the lab, although these correlations were not significant $(P>0.1$ in both cases).

among the seven traits. The same traits that were under selection for increasing values in the presence of Anax were exhibited by tadpoles in cattle tanks with caged Anax (Fig. 5A; $r_{\mathrm{s}}=0.79, P=0.036$ ), with the single exception of tail muscle width. Likewise, trait values that were correlated with enhanced growth in the competition experiment tended to be exhibited by tadpoles in predator-free ponds (Fig. 5B), although this pattern was not significant.

\section{DISCUSSION}

We have shown that dragonfly predation imposes selection on tail shape of Rana sylvatica tadpoles, and that the targets of selection are generally the same traits that 
display phenotypic plasticity in response to predators. At the same time, tadpoles exhibiting opposite combinations of traits grow faster in the absence of predators. We argue that plasticity could be maintained in natural populations by this kind of selection, but to make our argument plausible we must first address three issues. First, what sort of environmental variability do tadpoles experience in nature, and what does the nature of environmental variability imply about selection for plasticity? Second, what are the functional bases of selection favouring different traits in environments having different predation regimes? Finally, how can this argument be reconciled with two of our findings that contradict predictions of the adaptive plasticity hypothesis: weak or inconsistent selection in the absence of predators, and the lack of plasticity in one trait that is under strong selection by dragonflies?

\section{Natural variation in predation regime}

The natural distribution of predators among ponds creates a coarse-grained environment for anuran larvae, in which the predator regime varies among ponds and among years within ponds, but is relatively consistent within ponds over a single season. Lentic freshwater habitats can be arranged along a gradient defined by persistence, extending from ephemeral pools to permanent lakes (Wiggins, Mackay \& Smith, 1980; Wellborn, Skelly \& Werner, 1996). The persistence gradient is critically important for anuran larvae and many other aquatic organisms because it determines the distribution of predators. Invertebrate and vertebrate predators tend to be larger, more numerous, and more predictable in occurrence in more permanent ponds (Smith, 1983; Woodward, 1983; Skelly, 1996; Wellborn et al., 1996). As a group, these predators exact a heavy toll on tadpoles (Heyer, McDiarmid \& Weigman, 1975; Caldwell, Thorpe \& Jervey, 1980; Azevedo-Ramos et al., 1992; Gascon, 1992), and aeshnid dragonflies in particular can eliminate all tadpoles from natural ponds (Smith, 1983).

Within relatively temporary ponds, predators show a characteristic pattern of temporal abundance. Individual ponds contain highly variable numbers of predators, depending on recent history of drying and refilling (Harris, Alford \& Wilbur, 1988; Jefferies, 1994; Skelly, 1996). Following wet years, most ponds within a region contain high numbers of predators, whereas few predators are present immediately after an extended dry period. These large-scale rainfall patterns can dramatically affect the exposure of tadpoles to predators. Even though a few anurans display some habitat selection at the time of oviposition (Resetarits \& Wilbur, 1989; Hopey \& Petranka, 1994), the regional scale of hydroperiod cycles probably prevents frogs from entirely avoiding predators in some years. While temporary ponds may show some temporal variation in predators within seasons, they seem likely to contain a consistent predator fauna after an initial colonization phase. As a result, temporary pond anurans are exposed to a range of predation regimes over generations, but a more stable collection of predators during the larval period of any individual tadpole (Smith, 1983; Skelly, 1996).

Quantitative samples collected from natural ponds on our study area partially support this characterization of the predator environment for larval Rana sylvatica (Fig. 6). In both 1996 and 1997, many populations of $R$. sylvatica occurred in ponds 


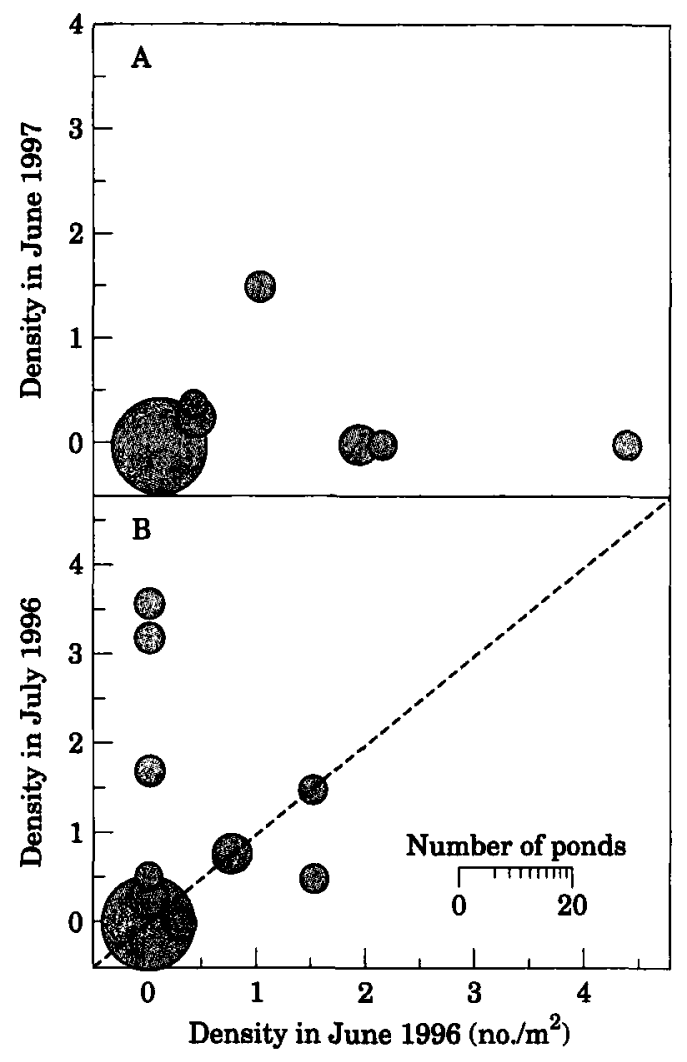

Figure 6. Densities of aeshnid dragonflies (Aeshna and Anax) in pipe-samples taken in natural ponds on the E.S. George Reserve in southern Michigan. The diameter of the bubbles represents the number of ponds having each value. Samples collected in June during both 1996 and 1997 for the 21 ponds that contained Rana syluatica tadpoles in both years (A) illustrated variation within and between years in the density of dragonflies. In both years there were ponds with and without aeshnids, and the density within some ponds changed considerably between years. Samples collected for 25 ponds during both June and July in 1996 (B) illustrated that aeshnid density generally increased or stayed the same within that year. The dashed line corresponds to identical densities in the June and July samples. These data were collected in collaboration with S.A. McGollum, D.K. Skelly, E.E. Werner, and K.L. Yurewicz.

with no aeshnid larvae, and a few populations were exposed to moderate densities of aeshnids. Predator numbers generally declined in 1997 as a result of a late-season drought in 1996, but there were examples of populations with both increasing and decreasing aeshnid density between the two years (Fig. 6A). Within 1996, the density of aeshnids remained consistent between the June and July samples in 22 of 25 ponds, primarily because many ponds had no dragonflies in either census (Fig. 6B). For these ponds, the environment was temporally autocorrelated within a season. But three other ponds had increasing dragonfly densities during the summer, resulting from growth of one-year-old Aeshna which were too small to be counted in the early June census. In terms of large dragonflies, then, the environment experienced by $R$. sylvatica can vary within ponds among years, and among ponds within years. For most populations the environment remains fairly consistent within years. 
Theory suggests that coarse-grained environmental variation of this sort is conducive to the evolution of phenotypic plasticity (Via \& Lande, 1985; Gomulkiewicz \& Kirkpatrick, 1992; Moran, 1992; Via et al., 1995). Models show that selection operating only within environments can favour genotypes that express the appropriate reaction norm across environments (Moran, 1992; Via et al., 1995). Such genotypes have phenotypes that are close to the optimum across a range of environments, and therefore experience relatively high fitness in all years and will increase in frequency relative to genotypes that possess optimal phenotypes only during some years.

With respect to predator density, the temporary pond system exhibits a combination of environmental variation (among years) and moderate autocorrelation (within years), both of which may be necessary for plasticity to evolve (Travis, 1994). Individual anuran larvae may be exposed to only a single environment or a slowly changing environment within their lives, but populations experience different numbers of predators in different years, and therefore undergo selection for plasticity. The widespread occurrence of predator-induced defences in organisms inhabiting temporary ponds (Dodson, 1989; McCollum \& Leimberger, 1997; DeWitt, 1998) strengthens our conclusion that plasticity is a plausible and likely evolutionary response to variation in predation regime in these habitats. Other features of aquatic habitats thought to promote the evolution of plasticity, such as the presence of reliable cues indicating the condition of the environment, are discussed elsewhere (Dodson, 1989; McCollum \& Leimberger, 1997).

\section{The functional causes of selection}

One reason we feel confident that selection by predators acts to maintain plasticity in Rana sylvatica is that the connection between trait variation and fitness variation has a clear causal basis. Functional relationships between predator escape and morphology are fairly well established in tadpoles, although based primarily on theoretical rather than empirical results. Basic locomotory performance features such as swimming speed, acceleration, and maneuverability are thought to depend on the same morphological traits that are targets of selection by feeding Anax. Because these measures of swimming performance are of general importance in predator escape (Feder, 1983; Weihs \& Webb, 1984; Watkins, 1996), we suspect that the facultative response to Anax found in this and other studies (McCollum \& Van Buskirk, 1996; Van Buskirk et al., 1997) may have evolved as a generalized induced response to variation in the overall predation regime.

Structures involved in acceleration, burst speed, and perhaps rapid turning are important for escaping sit-and-wait predators (Howland, 1974; Weihs \& Webb, 1984). Hydrodynamic analyses of swimming vertebrates show that the tapering muscle of the tail and the deepest part of the tail fin are used in sudden starts and turns (Weihs, 1972; Webb, 1984; Wassersug \& Hoff, 1985; Wassersug, 1989), although these features are apparently not critical for maintaining steady swimming (Blight, 1977; Wassersug, 1989). These results suggest that the anuran tail fin and tail muscle are important for escaping predators, and our data show that they are targets of selection imposed by predation. There are indications of a trade-off between swimming speed and maneuverability (Webb, 1984; Brown \& Taylor, 1995), which might constrain the responses that tadpoles could potentially evolve to multiple predators that hunt in different ways. 
Activity level and habitat selection also affect vulnerability to predators in anurans and other organisms (Wright \& O'Brien, 1982; McPeek, 1990; Anholt \& Werner, 1995), and many taxa show apparently adaptive behavioural responses to predators (Sih, 1987; Lima \& Dill, 1990; Werner \& Anholt, 1993). In this study we could not associate behavioural phenotypes with individuals, and thereby test for selection imposed by predators. This would be a worthwhile exercise, because there are good reasons for expecting behaviour and morphology to interact non-additively to influence individual fitness (Christiansen, 1965; Kingsolver, 1988; Brodie, 1992; McPeek, 1995). Such tests would have to be conducted in more natural settings, in which behavioural mechanisms of predator avoidance have the opportunity to be expressed.

\section{Results that contradict the adaptive plasticity hypothesis}

We obtained two results that conflict with expectations stemming from the adaptive plasticity hypothesis. The first of these was that tail muscle width underwent strong selection by Anax but displayed no plasticity (Fig. 4C). We are confident of this result, because previous work confirms that Rana sylvatica shows no flexibility in tail muscle width (R. A. Relyea, unpublished) and that predators select for wide tail muscles in other anurans (Van Buskirk et al., 1997). There may be a constraint that prevents tail muscle from widening during development, or a trade-off preventing the tail from evolving increased width. The possibility of such a constraint is supported by the observation that no anuran yet studied exhibits significant plasticity in tail muscle width. A plausible explanation is that increased tail muscle width can be obtained only at the cost of decreased tail flexibility, which is itself critical for sudden acceleration (Wassersug, 1989; Andraso, 1997).

A second result that contradicts the adaptive plasticity hypothesis is the inconsistent selection on plastic morphological traits in the absence of free-ranging predators. If plasticity is adaptive we expect to see different combinations of traits conferring the highest relative fitness in the presence and absence of predators. Both the competition trials and plasticity experiment demonstrated that the predator-induced phenotype was costly when free predators were absent, but the evidence for selection on particular morphological traits was weak. For example, predator-induced tadpoles were affected more severely than no-predator tadpoles by competing Rana catesbeiana, and in the plasticity experiment tadpoles in caged-Anax tanks survived more poorly and metamorphosed later than tadpoles in ponds without caged predators. Because predators were not actually killing tadpoles in either of these experiments, reduced rates of survival, growth, and development must have arisen from the physiological costs of responding to Anax, or of maintaining the predator-induced phenotype. In spite of costs associated with the entire suite of traits, though, we found selection on particular morphological traits only in the competition trials. In that experiment, reduced growth rates of deep-tailed tadpoles supported the adaptive plasticity hypothesis, but other traits did not so clearly affect growth, and there was no evidence that the response to competitors depended on a tadpole's morphology. In the plasticity experiment, our analyses were unable to associate specific traits with the reduced performance of the predator-induced phenotype. The targets of selection in the absence of predators may well include behavioural traits related to foraging activity and intake rates, which were not measured in this experiment. Taken 
together, our results support earlier findings that the predator-induced phenotype is costly (McCollum \& Van Buskirk, 1996), and they suggest that selection in the predator-free environment for morphological traits induced by that environment is measurable but relatively weak.

Theory states clearly that selection must be operating in both environments to maintain plasticity (Via \& Lande, 1985; Gomulkiewicz \& Kirkpatrick, 1992; Moran, 1992). If relatively large tail fins and tail muscles have no effect on fitness in the absence of predators, then selection imposed only in the presence of predators would produce tadpoles that have large tails in all environments (assuming that tail shape is genetically correlated across environments). The fact that tail shape is plastic in $R$. sylvatica and several other anurans implies that there must be at least occasional selection favouring individuals with small tails in predator-free ponds.

Results of numerous studies suggest that selection against individuals exhibiting induced responses to predators in predator-free environments may be weak and inconsistent (O'Brien et al., 1980; Lively, 1986b; Baldwin et al., 1990; Spitze, 1992). One reason for the variability among results may be that costs are often expressed as a decline in growth or reproduction (Harvell, 1990; Spitze, 1992), which are likely to depend on availability of resources or energy (Appleton \& Palmer, 1988; Stemberger, 1988; Pettersson \& Brönmark, 1997). Thus, the magnitude of costs (and presumably the importance of selection in predator-free environments) may be highly sensitive to resource levels. This might explain why studies of anuran larvae have obtained different results: Van Buskirk et al. (1997) detected weak selection against predator-induced traits in ponds without free predators, while this study found selection against just a single trait and for only one measure of performance. We suspect that selection in predator-free ponds is irregular in occurrence, is probably rather context-dependent, and may target different fitness components under different conditions. So far, theory is not informative on the issue of how often divergent selection across environments must be in place in order to maintain plasticity.

It is possible that selection favouring shallow-tailed tadpoles in predator-free ponds is in fact quite rare. Several mechanisms could account for the existence of plasticity in the absence of divergent selection. Plasticity may have originally evolved when there was strong divergent selection across environments, but subsequent evolutionary changes have reduced the cost of anti-predator responses (Simms, 1992). Also, selection against tadpoles having deep tail fins may be acting during other stages of the life cycle or on components of fitness that we did not measure. Simultaneous exposure to multiple species of predators or competitors in natural ponds might alter the combinations of traits that are favoured, as well as their reaction norms across environments. Finally, traits expressed in predator-free ponds may evolve as correlated responses to selection acting in other environments. If alleles favoured by selection in other environments have pleiotropic effects in predator-free environments, then non-adaptive phenotypes could be maintained in predator-free environments. The existence of consistent genetic correlations among trait values across environments in other organisms makes this mechanism appear at least plausible (Via, 1984; Trexler \& Travis 1990; Semlitsch, 1993; Andersson \& Shaw, 1994). 
We believe the evidence supports the hypothesis that plasticity in the morphology and behaviour of larval anurans represents an adaptation to environmental heterogeneity. There is now support for both assumptions of the adaptive plasticity hypothesis: that existing reaction norms are beneficial, and that they have been produced by natural selection. Studies of numerous anurans show that behavioural responses to predators improve individual survival (Hews, 1988; Lawler, 1989; Werner \& Anholt, 1993; Skelly, 1994). The plastic morphological shift in Hyla chrysoscelis is clearly beneficial, because the predator-induced phenotype survives better with predators and the no-predator phenotype survives better in ponds without free predators (McCollum \& Van Buskirk, 1996). The functional connections between tail morphology, swimming performance, and predator escape have been worked out in theory (Wassersug, 1989), and results from a flowtank experiment suggest that tadpoles with deep tail fins have higher swimming speed and stamina (McCollum \& Leimberger, 1997).

The present study indirectly supports the second assumption of the adaptive plasticity hypothesis by demonstrating that traits which show the greatest plasticity also undergo the strongest selection (Fig. 5). This does not prove that the current reaction norm in Rana sylvatica was produced by selection acting in the past, but it does support the general case that reaction norms of this type are produced by selection (Brandon \& Rausher, 1996).

\section{Plasticity and species diversity in anurans}

The role of species interactions in either promoting or limiting species diversity is an issue of long-standing interest. Comparative studies suggest that selection imposed by predators, such as we have measured in $R$. sylvatica, may be involved in divergence and speciation within anuran assemblages. The main evidence for this is that groups of closely-related species sort out such that the average phenotype of each species is appropriate for the predators in its environment. For example, the tadpoles of two Pseudacris species that partition a predation gradient in eastern North America exhibit fixed differences in behaviour and morphology that are consistent with selective differences between their habitats (Skelly, 1995; Smith \& Van Buskirk, 1995). Pseudacris triseriata occurs in temporary ponds with few predators, feeds actively, and has a shallow tail fin and tail muscle. Pseudacris crucifer occurs in more permanent ponds with higher numbers of predators, is inactive, and has a relatively large tail. Thus, phenotypic differences between the two species are exactly congruent with divergent selection on behaviour and morphology in environments with and without predators (Skelly, 1994; Anholt \& Werner, 1995; McCollum \& Van Buskirk, 1996; Van Buskirk et al., 1997; this study). In this case, then, and in others (McPeek, 1995, 1997), it appears that differences among species have evolved in response to variation in selection along a predation gradient, which highlights a positive role for species interactions in directing and probably promoting diversification.

To some extent, plasticity might serve to reduce species diversity as well. In the anuran system, for example, it is possible that plastic responses of tadpoles to the presence or absence of other species in the community act to limit diversity by reducing the number of potential species that can co-occur. Plasticity may allow a 
single species to occupy a broad range of environments, thus preventing new species from invading or evolving within some of those environments. In certain cases divergent selection regimes are hypothesized to promote plasticity (e.g. Via et al., 1995), whereas in other situations divergent selection leads to ecological separation, reproductive isolation, and eventual speciation (Futuyma \& Moreno, 1988; WestEberhard, 1986, 1989; Thompson, 1994; Schluter, 1996; Mopper, 1996). The circumstances that affect the likelihood of these alternative outcomes remain an important area for future research.

\section{ACKNOWLEDGEMENTS}

We are grateful to J. Moll for help with the field work, and to W. Blanckenhorn, D. Harvell, A. McCollum, S. Peacor, J. Travis, E. Werner, K. Yurewicz, and an anonymous referee for their comments on the manuscript. Many thanks to $A$. McCollum, D. Skelly, E. Werner, and K. Yurewicz for permission to use results from a collaborative field sampling effort. We appreciate the logistical support of the maintenance crew on the George Reserve. We were funded by a University of Michigan Block Grant and E.S. George Research Scholarship to R.A.R., and NSF grant DEB-9408397 (to McCollum, Werner, and J.V.B.).

\section{REFERENCES}

Andersson S, Shaw RG. 1994. Phenotypic plasticity in Crepis tectorum (Asteraceae): genetic correlations across light regimes. Heredity 72: 113-125.

Andraso GM. 1997. A comparison of startle response in two morphs of the brook stickleback (Culaea inconstans): further evidence for a trade-off between defensive morphology and swimming ability. Evolutionary Ecology 11: 83-90.

Anholt BR, Werner EE. 1995. Interaction between food availability and predation mortality mediated by adaptive behavior. Ecology 76: 2230-2234.

Appleton R, Palmer AR. 1988. Waterborne stimuli released by predatory crabs and damaged prey induce more predator-resistant shells in a marine gastropod. Proceedings of the National Academy of Sciences USA 85: 4387-4391.

Arnold SJ, Wade MJ. 1984. On the measurement of natural and selection: theory. Evolution 38: $709-719$.

Azevedo-Ramos, RD, Van Sluys M, Hero J-M, Magnusson WE. 1992. Influence of tadpole movement on predation by odonate naiads. Joumal of Herpetology 26: 335-338.

Baldwin IT, Sims CL, Kean, SE. 1990. The reproductive consequences associated with inducible responses in wild tobacco. Ecology 71: 252-262.

Baum DA, Larson A. 1991. Adaptation reviewed: a phylogenetic methodology for studying character macroevolution. Systematic Zoology 40: 1-18.

Berven KA. 1990. Factors affecting population fluctuations in larval and adult stages of the wood frog (Rana sylvatica). Ecology 71: 1599-1608.

Blight AR. 1977. The muscular control of vertebrate swimming movements. Biological Reviewes 52: $181-218$.

Bookstein FL. 1991. Morphometric tools for landmark data: geometry and biology. Cambridge: Cambridge University Press.

Bradshaw AD. 1965. Evolutionary significance of phenotypic plasticity in plants. Advances in Genetics 13: 115-155.

Brandon RN, Rausher MD. 1996. Testing adaptationism: a comment on Orzack and Sober. American Naturalist 148: 189-201. 
Brodie ED, III. 1992. Correlational selection for color pattern and antipredator behavior in the garter snake Thamnophis ordinoides. Evolution 46: 1284-1298.

Brown RM, Taylor, DH. 1995. Compensatory escape mode trade-offs between swimming performance and maneuvering behavior through larval ontogeny of the wood frog, Rana syluatica. Copeia 1995: 1-7.

Caldwell JP, Thorpe JH, Jervey TO. 1980. Predator-prey relationships among larval dragonflies, salamanders, and frogs. Oecologia 46: 285-289.

Christiansen K. 1965. Behavior and form in the evolution of cave Collembola. Evolution 19: 529-537.

De Witt TJ. 1998. Costs and limits of phenotypic plasticity: tests with predator-induced morphology and life-history in a freshwater snail. Joumal of Evolutionary Biology 11: 465-480.

Dobzhansky T. 1951. Genetics and the origin of species. New York: Columbia University Press.

Dodson SI. 1989. Predator-induced reaction norms. BioScience 39: 447-452.

Dudley SA, Schmitt J. 1996. Testing the adaptive plasticity hypothesis: density-dependent selection on manipulated stem length in Impatiens capensis. American Naturalist 147: 445-465.

Falconer DS, Mackay TFC. 1996. Introduction to quantitative genetics, 4th ed. Essex: Longman.

Feder ME. 1983. The relation of air-breathing and locomotion to predation on tadpoles, Rana berlandieri, by turtles. Physiological Zoology 56: 522-531.

Futuyma DJ, Moreno G. 1988. The evolution of ecological specialization. Annual Review of Ecology and Systematics 19: 207-233.

Galloway LF. 1995. Response to natural environmental heterogeneity: maternal effects and selection on life history characters and plasticities in Mimulus guttatus. Evolution 49: 1095-1107.

Gascon C. 1992. Aquatic predators and tadpole prey in central Amazonia: field data and experimental manipulations. Ecology 73: 971-980.

Gomulkiewicz R, Kirkpatrick M. 1992. Quantitative genetics and the evolution of reaction norms. Evolution 46: 390-411.

Gosner K. 1960. A simplified table for staging anuran embryos and larvae with notes on identification. Herpetologica 16: 183-190.

Harris RN, Alford RA, Wilbur HM. 1988. Density and phenology of Notophthalmus viridescens dorsalis in a natural pond. Herpetologica 44: 234-242.

Harvell CD. 1986. The ecology and evolution of inducible defenses in a marine bryozoan: cues, costs, and consequences. American Naturalist 128: 810-823.

Harvell CD. 1990. The ecology and evolution of inducible defenses. Quarterly Review of Biology 65: 323-340.

Hews DK. 1988. Alarm response in larval western toads, Bufo boreas: release of larval chemicals by a natural predator and its effect on natural capture efficiency. Animal Behaviour 36: 125-133.

Heyer WR, McDiarmid RW, Weigman DL. 1975. Tadpoles, predation, and pond habitats in the tropics. Biotropica 7: 100-111.

Hopey ME, Petranka JW. 1994. Restriction of wood frogs to fish-free habitats: how important is adult choice? Copeia 1994: 1023-1025.

Howland HC. 1974. Optimal strategies for predator avoidance: the relative importance of speed and maneuverability. Foumal of Theoretical Biology 74: 333-350.

Jefferies M. 1994. Invertebrate communities and turnover in wetland ponds affected by drought. Freshwater Biology 32: 603-612.

Kingsolver JG. 1988. Thermoregulation, flight, and the evolution of wing pattern in pierid butterflies: the topography of adaptive landscapes. American Zoologist 28: 899-912.

Kingsolver JG. 1995. Fitness consequences of seasonal polyphenism in western white butterflies. Evolution 49: 942-954.

Lawler SP. 1989. Behavioural responses to predators and predation risk in four species of larval anurans. Animal Behaviour 38: 1038-1047.

Leroi AM, Rose MR, Lauder GV. 1994. What does the comparative method reveal about adaptation? American Naturalist 143: 381-402.

Levins R. 1968. Evolution in changing environments. Princeton: Princeton University Press.

Lewontin RC. 1978. Adaptation. Scientific American 239: 156-169.

Lima SL, Dill LM. 1990. Behavioral decisions made under the risk of predation: a review and prospectus. Canadian Foumal of Zoology 68: 619-640.

Lively CM. 1986a. Canalization versus developmental conversion in a spatially-variable environment. American Naturalist 128: 561-572.

Lively CM. 1986b. Competition, comparative life histories, and maintenance of shell dimorphism in a barnacle. Ecology 67: 858-864. 
Mantel N. 1967. The detection of disease clustering and a generalized regression approach. Cancer Research 27: 209-220.

McCollum SA, Leimberger JD. 1997. Predator-induced morphological changes in an amphibian: predation by dragonflies affects tadpole color, shape, and growth rate. Oecologia 109: 615-621.

McCollum SA, Van Buskirk J. 1996. Costs and benefits of a predator-induced polyphenism in the gray treefrog Hyla chrysoscelis. Evolution 50: 583-593.

McPeek MA. 1990. Behavioral differences between Enallagma species (Odonata) influencing differential vulnerability to predators. Ecology 71: 1714-1726.

McPeek MA. 1995. Morphological evolution mediated by behavior in the damselflies of two communities. Evolution 49: 749-769.

McPeek MA. 1997. Measuring phenotypic selection on an adaptation: lamellae of damselflies experiencing dragonfly predation. Evolution 51: 459-466.

Mopper S. 1996. Adaptive genetic structure in phytophagous insect populations. Trends in Ecology and Evolution 11: 235-238.

Moran NA. 1992. The evolutionary maintenance of alternative phenotypes. American Naturalist 139: 971-982.

Newman RA. 1992. Adaptive plasticity in amphibian metamorphosis. BioScience 42: 671-678.

O'Brien WJ, Kettle D, Riessen H, Schmidt D, Wright D. 1980. Dimorphic Daphnia longiremis: predation and competition interactions between two morphs. In: Kerfoot WC ed. Evolution and ecology of zooplankton communities. Hanover: University Press of New England, 497-505.

Peacor SD, Werner EE. 1997. Trait-mediated indirect effects in a simple aquatic food web. Ecology 78: 1146-1156.

Pettersson LB, Brönmark C. 1997. Density-dependent costs of an inducible morphological defense in crucian carp. Ecology 78: 1805-1815.

Resetarits WJ, Wilbur HM. 1989. Choice of oviposition site by Hyla chrysoscelis: role of predators and competitors. Ecology 70: 220-228.

Schluter D. 1996. Ecological causes of adaptive radiation. American Naturalist 148: S40-S64.

Schmitt J. 1993. Reaction norms of morphological and life-history traits to light availability in Impatiens capensis. Evolution 47: 1654-1668.

Schmitt J, McCormac AC, Smith H. 1995. A test of the adaptive plasticity hypothesis using transgenic and mutant plants disabled in phytochrome-mediated elongation responses to neighbors. American Naturalist 146: 937-953.

Scott DE. 1994. The effect of larval density on adult demographic traits in Ambystoma opacum. Ecology 75: $1383-1396$.

Semlitsch RD. 1993. Adaptive genetic variation in growth and development of tadpoles of the hybridogenetic Rana esculenta complex. Evolution 47: 1805-1818.

Semlitsch RD, Scott DE, Pechmann JHK. 1988. Time and size at metamorphosis related to adult fitness in Ambystoma talpoideum. Ecology 69: 184-192.

Semlitsch RD, Harris RN, Wilbur, HM. 1990. Paedomorphosis in Ambystoma talpoideum: maintenance of population variation and alternative life-history pathways. Evolution 44: 1604-1613.

Sih A. 1987. Predators and prey lifestyles: an evolutionary and ecological overview. In: Kerfoot WC, Sih A eds. Predation: direct and indirect impacts on aquatic communities. Hanover: University Press of New England, 203-224.

Simms EL. 1992. Costs of plant resistance to herbivory. In: Fritz RS, Simms EL, eds. Plant resistance to herbivores and pathogens: ecology, evolution, and genetics. Chicago: University of Chicago Press, 392-425.

Skelly, DK. 1994. Activity level and the susceptibility of anuran larvae to predators. Animal Behaviour 47: 465-468.

Skelly, DK. 1995. A behavioral trade-off and its consequences for the distribution of Pseudacris treefrog larvae. Ecology 76: 150-164.

Skelly, DK. 1996. Pond drying, predators, and the distribution of Pseudacris tadpoles. Copeia 1996: 599-605.

Skelly DK, Werner EE. 1990. Behavioral and life historical responses of larval American toads to an odonate predator. Ecology 71: 2313-2322.

Smith DC. 1983. Factors controlling tadpole populations of the chorus frog (Pseudacris triseriata) on Isle Royale, Michigan. Ecology 64: 501-510.

Smith DG. 1987. Adult recruitment in chorus frogs: effects of size and date at metamorphosis. Ecology 68: 344-350.

Smith DC, Van Buskirk J. 1995. Phenotypic design, plasticity, and ecological performance in two tadpole species. American Naturalist 145: 21 1-233. 
Spitze K. 1992. Predator-mediated plasticity of prey life history and morphology: Chaoborus americanus predation on Daphnia pulex. American Naturalist 139: 229-247.

Stearns SC. 1989. The evolutionary significance of phenotypic plasticity. BioScience 39: 436-445.

Stemberger RS. 1988. Reproductive costs and hydrodynamic benefits of chemically induced defenses in Keratella testudo. Limnology and Oceanography 33: 593-606.

Thompson JN. 1994. The coevolutionary process. Chicago: University of Chicago Press.

Travis J. 1994. Evaluating the adaptive role of morphological plasticity. In: Wainwright PC, Reilly SM, eds. Ecological morphology. Chicago: University of Chicago Press, 99-122.

Trexler JC, Travis J. 1990. Phenotypic plasticity in the sailfin molly, Poecilia latipinna (Pisces: Poeciliidae). I. Field experiments. Evolution 44: 143-156.

Van Buskirk J, McCollum SA, Werner EE. 1997. Natural selection for environmentally-induced phenotypes in tadpoles. Evolution 51: 1983-1992.

van Tienderen PH. 1997. Generalists, specialists, and the evolution of phenotypic plasticity in sympatric populations of distinct species. Evolution 51: 1372-1380.

Via S. 1984. The quantitative genetics of polyphagy in an insect herbivore. I. Genotype-environment interaction in larval performance on different host species. Evolution 38: 881-895.

Via S, Lande R. 1985. Genotype-environment interaction and the evolution of phenotypic plasticity. Evolution 39: 505-522.

Via S, Gomulkiewicz R, De Jong G, Scheiner SM, Schlichting CD, Van Tienderen PH. 1995. Adaptive phenotypic plasticity: consensus and controversy. Trends in Ecology and Evolution 10: 212-217.

Wassersug RJ. 1989. Locomotion in amphibian larvae (or "Why aren't tadpoles built like fishes?"). American Zoologist 29: 65-84.

Wassersug RJ, Hoff K. 1985. Kinematics of swimming in anuran larvae. Journal of Experimental Biology 119: $1-30$.

Watkins TB. 1996. Predator-mediated selection on burst swimming performance in tadpoles of the pacific tree frog, Pseudacris regilla. Physiological Zoology 69: 154-167.

Webb PW. 1984. Body form, locomotion, and foraging in aquatic vertebrates. American Zoologist 24: $107-120$.

Weihs D. 1972. A hydrodynamical analysis of fish turning manoevres. Proceedings of the Royal Society (London), Series B 182: 59-72.

Weihs D, Webb PW. 1984. Optimal avoidance and evasion tactics in predator-prey interactions. Journal of Theoretical Biology 106: 189-206.

Wellborn GA, Skelly DK, Werner EE. 1996. Mechanisms creating community structure across a freshwater habitat gradient. Annual Review of Ecology and Systematics 27: 337-363.

Werner EE, Anholt BR. 1993. Ecological consequences of the tradeoff between growth and mortality rates mediated by foraging activity. American Naturalist 142: 242-272.

West-Eberhard MJ. 1986. Alternative adaptations, speciation, and phylogeny. Proceedings of the National Academy of Sciences 83: 1388-1392.

West-Eberhard MJ. 1989. Phenotypic plasticity and the origins of diversity. Annual Review of Ecology and Systematics 20: 249-278.

Wiggins GB, Mackay RJ, Smith IM. 1980. Evolutionary and ecological strategies of animals in annual temporary ponds. Archiv fur Hydrobiologie, Supplement 58: 97-206.

Williams GC. 1966. Adaptation and natural selection. Princeton: Princeton University Press.

Woodward BD. 1983. Predator-prey interactions and breeding-pond use of temporary-pond species in a desert anuran community. Ecology 64: 1549-1555.

Wright DI, O'Brien WJ. 1982. Differential location of Chaoborus larvae and Daphnia by fish: the importance of motion and visible size. American Midland Naturalist 108: 68-73.

Wright S. 1931. Evolution in mendelian populations. Genetics 16: 97-159. 